\title{
COOPERATIVISMO E COMUNIDADE
}

\author{
Oto de Brito Guerra \\ Professor de Direito Civil da Faculdade de Direito \\ de Natal \\ I - Senso Comunitário e Subsidiariedade
}

Quanto maior a crise atual, mais urge a conjugação de esfôrços, em busca de soluções capazes de promover o bem estar individual e social. Tomam crescente voga os organismos internacionais, principalmente os da O. N. U., tais como a F. A. O., para a agricultura, a U. N. E. S. C. O., para a educação, a O. M. S., para a saúde, a O. I. T., para as relações do trabalho, desenvolvem-se as técnicas ligadas à planificação econômica e social, depositam-se as melhores esperanças, principalmente com relação a zonas subdesenvolvidas, nos processos, altamente democráticos e educativos, do Serviço Social de Comunidade e no trabalho global que visa a Organização Social da Comunidade.

Forma-se a convicção de que é indispensável uma integração pessoal maior na orgânica de cada um dos muitos grupos sociais a que pertencemos, - a família, a vizinhança, a escola, o grupo profissional, o grupo de recreio, o grupo religioso, etc., sob a pena de falhas insanáveis no justo equilíbrio individual e social. Uma integração que importa, simultâneamente, na ação de cada pessoa sôbre cada um dos seus grupos, na ação de cada um dêsses grupos sôbre cada pessoa, finalmente na integração de cada um dêstes na comunidade. 
Tudo se passando de maneira que não se deixe para aquêle grupo social imediatamente superior, qualquer das tarefas que possam, ou devam ser executadas pelo grupo menor. Nem, muito menos, se concorde em que os grupos maiores venham usurpar, ou assumir funções que não lhes sejam próprias. Tal como ocorrer frequentemente, com o Estado, por isso mesmo sobrecarregado duma infinidade de tarefas "extra", atribuíveis aos grupos menores esvasiados, infelizmente, de muitas de suas responsabilidades insubstituíveis. É o caso, por exemplo, da crescente demissão da família, no mundo moderno.

Pio XI ocupou-se na "Quadragésimo Anno", (1) dêste lídimo princípio social cristão, a subsidiaridade ou função supletiva dos grupos, fórmula eminentemente pluralista, muito superior ao individualismo e ao socialismo, para não falar no con:unismo, decorrência dêste último. Princípio que não se estanca no acatamento da comunidade maior a tudo quanto seja atribuível à comunidade menor, porém vai mais longe, reclamando o respeito do menor dos grupos sociais àquilo que a pessoa humana, tomada individualmente, deva realizar.

Portanto, respeito e, mais que isso, incentivo ao fiel desempenho da vocação de cada pessoa e de cada grupo, um pluralismo, dentro do melhor espírito comunitário, realizando a unidade na variedade.

Integrando-se nos grupos constitutivos de sua comunidade, cáda um receberá substancial ajuda, multiplicando, quase ao infinito, o seu valor pessoal, a sua capacidade de servir. Por cutro lado, numa espécie de contra-prestação, cooperará, pela sua contribuição pessoal, para o maior rendimento social do grupo e da comunidade, para maior riqueza de tudo, oferecendo-lhe quanto fôr capaz, em experiência, talento, cultura e dedicação. Mac Iver, no livro "Comunidade", descreve o fenôme-

(1) Pio XI, encíclica "Quadragésimo Anno", n.o 79. Vêr sôbre o assunto: "O princípio da subsidiariedade ", art. de Franz H. Mueller, in Serviço Social (rev.) n. ${ }^{\circ}$ 44, III de 1947, p. 3; Eberhard Welty "Catecismo-Social", Tomo primeiro, n. 52; Oswald Von Nell Breuning, "La Reorganizacion de la Economia Social" p. 234. 
no como segue: "assim como cada um de nós faz a sua sociedade, esta, por sua vez, nos faz a cada um de nós. Se nossa individualidade é poderosa, fortalece a nossa sociedade e vice-versa; e à nossa sociedade devemos, correspondentemente, a nossa individualidade". (2).

\section{II - Comunidade e Cooperativismo}

Falta, a muitos, noção real do que seja uma comunidade, aferrados, que são, a princípios individualistas ou coletivistas. E pouca gente sabe apreciar, no Brasil, as vantagens duma bôa organização de comunidade, que é um planejamento global.

Fora daquilo que tantos consideram estrita obrigação dos govêrnos (federal, estadual, municipal) parece-lhes utopia pensar na conjugação de esforços privados para melhoria efetiva das condições de vida de uma determinada população, mediante processos de organização e planejamento da comunidade.

Aliás, não deve a comunidade ser tida como simples grupo de vizinhança. Sua noção é muito mais complexa, reclamando a integração de um certo número de requisitos ou elementos, de que José Artur Rios, em seu notável livro "A Educação dos Grupos", deu minusciosa enumeração: a) um grupo humano; b) uma área geográfica contígua; c) uma trama de relações c contatos íntimos; d) a mesma tradição e os mesmos interêsses; e) uma consciência dessa participação nos ideais e valores comuns. (3).

Encarando a realidade brasileira, mostrou o mesmo autor, quais as características da comunidade, em nossa terra: a) uma área territorial, caracterizada por uma séde urbana, onde se localizam os principais serviços e instituições, o ginásio, a escola, a igreja, as repartições do govêrno, a Prefeitura, as agências recreativas, o mafuá, o cinema, a coletoria, os diferentes

(2) MacIVER, "Comunidad", p. 238.

(3) José Artur Rios, "A Educação dos Grupos", p. 80. 
serviços de saúde e assistência, etc., as residências das famílias mais prósperas do município, as agências econômicas e bancos, o comércio. Para a séde urbana convergem as vizinhanças ou famílias isoladas da zona rural; b) Essa área geográfica é completada por uma área social, representada pelos grupos de vizinhança, que têm a consciência de se articular com o centro urbano; finalmente, c) um certo consenso de opinião, que se reflete nas àtitudes e reações coletivas, ante os problemas do bem comum local. (4).

É oportuno recordar que também as cooperativas possuem uma área de ação, uma dimensão geográfica, econômica e social, dentro da qual se inscreverão os seus associados e êstes a buscarão para seus negócios (5). Aqui, no Brasil, essa área coincide, geralmente com a extensão do próprio município ou dostrito em que estiver sediada.

\section{III - Planejamento Comunitário e Cooperativismo}

É tempo de indagar que relações práticas se apontam entre a organização da comunidade e a cooperativa. Nada mais claro. Pois conforme SANDERSON E POLSON, citados no livro clássico de HILLMAN, (6), a organização da comunidade é uma técnica para obter a opinião da mạioria sôbre os valôres mais importantes para o bem comum e os melhores meios de ser êste realizado. Portanto, ação em comum, cooperação geral. Ora, a cooperativa reclama, justamente, conjugação do esforço mútuo, elevado espírito de serviço, ação em comum, vi-

(4) José Artur Rios, "A Educação dos Grupos", p. 91; Hillman, "Organização da Comunidade e Planejamento", observa que "a unidade econômica e social funcional, dentro de uma área, pode transender os limites traçados pela divisão territorial" - p. 21 da edição brasileira.

(5) A influência econômica e social da cooperativa, òbviamente, é muito maior do que a área fixada pelos Estatutos para a aceitação de sócios, principalmente a sua função educativa.

(6) "Organização da Comunidade e Planejamento", de Arthur Hillman, p. 28. 
sando não apenas o bem estar econômico, mas, acima de tudo, a elevação global do teor de vida humana, rasgando novos horizontes, pela educação popular, sempre em luta contra a rotina, a inércia, o derrotismo.

Reunem-se na cooperativa os mesmos elementos de desenvolvimento econômico, as mesmas virtudes sociais (espírito de entre-ajuda, senso de responsabilidade) que reclama a organização da comunidade. Ademais, o povo aprende a refletir, a ter sua opinião, a colaborar com o semelhante e com o poder público.

Eis porque sua excia. D. José de Medeiros Delgado, em seu livro "O Homem e a Comunidade", não hesita em enumerar as Cooperativas, do Crédito, Produção ou Consumo, entre as instituições ou agências indicadas para uma organização comunitária das pessoas, tais como os Centros Sociais, Conselhos de Comunidade, Serviços Coletivos, Escolas, para acentuar que, em tôdas elas, as bôas vontades se colocam em comunhão, em ebulição, em clima comunitário. (7).

Não é preciso dizer mais para justificar-se a inclusão das cooperativas em qualquer plano completo e eficiente de interrelacionamento comunitário.

\section{IV - Cooperativismo e educação democrática}

O signo do economismo, sob o qual vivemos, obscurece várias facêtas da instituição cooperativa. Deixa mais à mostra seus aspectos econômicos, ainda assim desvirtuados, tanta vez, pela substituição do sadio espírito de serviço, pelo mero espírito de lucro e de interêsse.

Aparece a muitos, a cooperativa, como sendo um estabelecimento bancário, igual aos outros e o associado tão só um

(7) Dom José de Medeiros Delgado, "O Homem e a Comunidade", p. 141. São também valiosas, como ponto de partida para muitas reflexões, as observações contidas no folheto "Cooperativismo e Desproletarização", do mesmo Arcebispo. 
cliente, ávido de bons negócios pessoais, de juros do capital, de retôrno, de lucros. Quando o principal, no cooperativismo, é sua tarefa educativa, salientada, em seu tríplice aspecto, por 'Fernando Chavez Nunez, em folheto divulgado pela União Panamericana, de Washington: a) o cooperativismo é importante fatôr de robustecimento da democracia; b) é um elemento valioso de integração dos grupos humanos nas comunidades onde estiver funcionando; c) é uma escola viva de capacitação cultural. (8).

Realmente, o cooperativismo constitui órgão eminentemente democrático, nunca é demais insistir. A visão genial dos seus pioneiros, antecipou-se de um século, ao firme desejo de sindicar e corrigir as atividades dos dirigentes, de colaborar mais eficazmente nos destinos dos individuos e das sociedades, que c Papa Pio XII, na sua Radiomensagem de 1944, assinalava como sendo uma das características do homem de nossos dias. (9).

É só examinar os célebres princípios fundamentais, lançados pelos operários tecelóes de Rochdale, tão conhecidos de qualquer cooperativista e ainda hoje, com pequena revisão posterior, as regras de ouro do movimento, e ver-se-á quanta razão tinha Gide, ao dizer que o cooperativismo nasceu das entranhas do povo.

(8) Fernando Chavez Nunez, "La institucion cooperativa y la educacion de adultos" in Folheto "Cooperativas", n. ${ }^{\circ}$ 7, II de 1950 da União Panamericana, p. 15.

(9) Pio XII, Radiomensagem do Natal, 1944, in Osservatore Romano de 25 de XII de 1944.

"Os povos como que despertaram de um longo torpor. Tomaram diante do Estado e dos governantes uma nova atitude interrogativa, crítica, desconfiada. Ensinados por uma experiência amarga, opõem-se com maior violência aos monopólios de um poder ditatorial, indevassável e intangível, e requerem um sistema de govêrno mais compatível com a dignidade e liberdade dos cidadãos. Estas multidões irrequietas estão hoje dominadas pela persuasão... de que, se não tivesse faltado a possibilidade de sindicar e corrigir a atividade dos poderes públicos o mundo não teria sido arrastado na voragem desastrosa da guerra". 
Graças ao sistema de freios e contra-pesos adotado, a cooperativa oferece um amplo contrôle democrático, muito superior a quaisquer outros tipos de sociedade. E se, na pratica, nem sempre êles são, de fato exercidos, a culpa não reside na instituição, porém no seu desvirtuamento, por ignorância, displicência ou má fé.

Assim é que temos o princípio da livre adesão, também chamado "da porta aberta": cada associado subscreve e integralisa sua quota parte livremente, a qual formará, com as de muitos outros, o capital social; e retirar-se-á quando lhe aprouver, também livremente. Por outro lado, qualquer que seja o montante das quotas partes de um associado, cada um, entretanto, grande ou pequeno, sòmente tem direito a um voto, nas assembléias e decisões, todos, portanto, em absoluto pé de igualdade: é o princípio do voto singular.

Graças ao mecanismo do retôrno pelo qual a participação nos lucrọ da instituição é proporcional à utilização dos serviços pelo associado, portanto, à atividade pessoal e não ao capital subscrito de cada um, a ambição do lucro não pode inocular o seu veneno, como ocorre nas sociedades capitalistas, tanto mais quanto o próprio capital dos associados tem um juro fixo e limitado.

Finalmente, não esqueçamos que deve dada assembléia permitir a livre e honesta discussão dos problemas, sem subserviências, coações ou segundas intenções. Nela, o associado aprende a encarar com naturalidade os fatos do seu próprio interêsse pessoal, da sua família, juntamente com os de seus companheiros, da comunidade inteira, confirmando o juízo de Carmem Varriale, num estudo sôbre Serviço Social e Cooperativismo: "Tôda associação cooperativista é um instrumento de permanente aperfeiçoamento social e moral de seus membros" (10).

(10) Carmen C. Varriale, "Serviço Social e Cooperativismo". in Tomas Cooperativos, p. 64. 
Tudo isto vem comprovar o importante papel que a cooperativa desempenha na integração de seus associados na comunidade para a qual funciona. Fundada para a consecução de objetivos bem definidos, crédito, consumo, produção, habitação, fins escolares, etc., ela acostuma o sócio a enfrentar cotidianamente os problemas do seu meio, confiante na ação conjunta, interessando-o pela melhoria econômica pessoal e também dos companheiros, pela discussão democrática das questões, enfim, capacitando-o culturalmente, cada vez melhor.

\section{$V$ - As derivações pessoais}

Não é tudo. Devem as cooperativas desenvolver aquelas “derivações sociais", tão incisivamente recomendadas pelo "Manifesto da Vida Rural", lançado, nos Estados Unidos, pela Conferência Católica da Vida Rural, como sejam o teatro, o canto, a música, a literatura, as escolas populares (11). Formação, cultura, recreação.

Como seria interessante uma constante ligação de cada cooperativa ou pelo menos das principais, a título experimental, com as Escolas de Serviço Social e com assistentes sociais, para um trabalho de grupo e de comunidade com os seus associados, à base dessas "derivações sociais", para a melhor formação democrática! (12).

A própria fundação de uma cooperativa, se se deseja um alicerce mais firme, deve ser precedida de estudos e debates,

(11) La cristianizacion de la vida rural, manifesto editado pela "Associação Católica da vida rural dos Estados Unidos”, p. 185, n. 155.

(12) 0 processo de Serviço Social de Grupo é dos mais interessantes, existindo farta bibliografia sôbre o mesmo. A União Panamericana pelo seu "Conselho Interamericano Econômico e Social", editou interessante folhêto: "Serviço Social de Grupo" por Dorothea F. Sullivan. Relativamente à educação de adultos, a Divisão de Educação da União Panamericana fêz editar, de autoria de Guillermo Nannett, um bem feito "Manual de Educación de Adultos". 0 livro de José Artur Rios, já citado, é entretanto o que de melhor se pode encontrar. 
em tôrno dos temas específicos de cooperativismo, tão importantes, mas também daquêles decorrentes de um levantamento geral dos problemas da comunidade, mediante inquéritos, sondagens de opinião, trabalhos em equipe, descoberta e formação de líderes, enfim tôda aquela técnica já provada, que o Serviço Social inculca, em qualquer um dos seus três métodos: caso individual, grupo e comunidade.

Os clubes ou circulos de estudo prestarão ao movimento cooperativista serviço inestimável, permitindo, ademais, um conhecimento seguro de todos os problemas da comunidade, mesmo aparentemente alheios à cooperativa, emergindo as soluções do desenvolvimento dos debates.

Clubes êsses que não devem existir, apenas, na fase preliminar da fundação, é bom que se diga. Eles são permanentemente úteis a qualquer cooperativa que não se deixe absorver pelo economismo, constituindo-se o melhor elemento de capacitação dos associados, principalmente em país de escassa formação social como o nosso, alimentando a chama do entusiasmo, acostumando cada participante ao clima do debate franco, aberto, objetivo, bem informado, de todos os problemas que venham a surgir. Eis porque são êles chamados de "universidade do povo".

A falta de estudo, o escasso hábito de leitura da noss a gente, mais ainda justifica debates desta natureza. Ademais, experiências feitas nos Estados Unidos comprovam que o estudo dos probemas em grupo ministra, aproximadamente, $17 \%$ de informação a mais do que o estudo isolado, retendo-se cerca da 56\% das mesmas, por um período até de seis mêses. (13).

Em seus numerosos livros, Waldiki Moura (14), conta o que existe nos Estados Unidos, Canadá, diversos países da Europa, relativamente a êsses Clubes, ótimos fatôres de educa-

(13) Fernando Chavez Nunez, "Los Circulos de Estudio" in Cooperativas, número 7, II de 1950, p. 10.

(14) Valdiki Moura, "Diretrizes Cooperativistas" (notas e comentários), "10 Faces do Mundo" (uma visão da terra e da gente - aspectos do movimento cooperativo), "Edificação do Mundo Socialista". 
ção de adultos, discutindo e apontando soluções em assuntos relacionados com a lavoura, a pecuária, a indústria, o consumo de alimentos, a colocação de produtos, o incremento da policultura, a atuação dos grupos na sociedade, a melhoria das condições de vida da família, o cooperativismo e o Estado, e assim por diante.

$\mathrm{Na}$ Suécia, por exemplo, $60 \%$ das cooperativas adotam 0 sistema dos clubes de estudo e de treinamento prático, existindo, a cargo da "Kooperativa Forbundet" uma grande escola, que ministra constantemente cursos de cooperativismo e que já preparou mais de 31 mil líderes cooperativistas. Também são dados cursos para as donas de casa e em tôrno dos seus problemas específicos se lançam outros, inclusive preocupações de fins humanitários, como é o caso das senhoras que angariam fundos para as pesquisas de combate ao câncèr.

Poderíamos referir também o que faz a grande organização católica da Bélgica, o Boerembond, ou "União dos Agricultores", com suas cooperativas, seus serviços de assistência técnica, social, previdenciária, sua imprensa especializada, a formação religiosa dos seus membros. Seria, porém, alongar demasiado o presente trabalho. Aí estão os livros de Waldiki Moura com um relato de tudo quanto viu, ou leu para não citar outros. Que a famosa experiência com os pescadores e mineiros de Antigonish, Canadá, pela Universidade dos Jesuítas, também não seja esquecida.

Costumam dizer os céticos e desiludidos, que tudo isto é muito bonito e possível, porém nos povos mais adiantados. Mas que a nossa gente não está absolutamente em condições de realizar coisas ao menos parecidas. E que o próprio cooperativismo, como se vem praticando, entre nós, desapareceria, sem a assistência e o auxílio governamental.

Acreditamos que já seja possível, no Brasil, colher depoimentos valiosos e elucidativos dêstes bravos sacerdotes, assistentes sociais, médicos, agrônomos, educadores familiares, enfim de quantos, apóstolos e técnicos, trabalham nas Missões Rurais, nos Centros Sociais, na Ancar e organizações semelhantes de crédito supervisionado, nos Conselhos de Comunidade, 
sôbre a capacidade real do nosso povo em despertar para êsse novo mundo da auto-determinação. Parece-nos que sòmente lhe falta, isto sim, preparação bastante, cada vez mais intensiva, para sua maioridade, reprentando as experiências feitas, até agora, alguns poucos oásis num imenso deserto. Mas oásis que devem ser multiplicados, como verdadeiras experiência-pilôto, capazes de convencer aos mais céticos.

Tomemos, a propósito, o depoimento valioso, saber "de experiências feito", de D. José de Medeiros Delgado, arcebíspo do Maranhão, antigo bispo de Caicó, antigo vigário de Campina Grande, cuja dedicação dos problemas de ascenção do povo, no sentido anti-demagógico e cristão do têrmo, bem justificam a presidência muito honrosa do Secretariado de Ação Social na Conferência Nacional dos Bispos. Diz sua Excia., em seu livro "O Homem e a Comunidade":

"Era comum ouvir-se, até de lábios que deviam guardar sabedoria, que é inútil esperar o desenvolvimento popular. Os pequeninos, sempre massa, terão que ser a vida inteira, tangidos. 0 que urge é garantir-lhes bons governantes. Tirá-los da mediocridade, do rudimentar, da rotina é utopia". (15).

No entanto, êsse incansável apóstolo e trabalhador social não concorda com semelhante opinião pessimista, apesar de todos os obstáculos, provações, desilusões e incompreensões que tenha encontrado, como desafio á sua tenacidade sertaneja. Ele inculca a necessidade, inclusive no terreno do apostolado religioso, de proclamar nos fiéis (e portanto no povo em geral) a sua "maioridade espiritual, moral, intelectual, social, econômica, cultural, civil e religiosa", mostrando que, "para alívio em muitos, espanto em vários, descoberta em todos”, se encontrará o filósofo e o político em cada sêr humano, por mais rude que êle seja, e se verificará quanta capacidade existe na gente humilde. (16).

(15) Don José de Medeiros Delgado, "O Homem e a Comunidade", p. (I6) idem, idem. 


\section{$V I$ - O defeito e sua correção}

Não está o defeito em nosso povo, nas suas qualidades pessoais. Pelo contrário, quantos estudam o brasileiro lhe exaltam qualidades. As causas do nosso atrazo portanto residem noutros fatôres.

O professor Lynn Smith, da Universidade de Luisiana, Estados Unidos, autor de notável livro sôbre nossa terra, (17), deu, num pequeno estudo sôbre "A Organização de atividades de bem estar rural na América Latina" (18), um rápido apanhado sôbre algumas dessas causas.

A primeira, em ordem e em importância, foi enumerada como sendo "a posse concentrada de terras e por conseguinte o rebaixamento da massa do povo ao nível de mero trabalhador rural"; resultado é que a falta de controle, pelos próprios habitantes, da comunidade, das fôrças básicas que determinam 0 seu bem estar, (dada a concentração da posse da terra), impede o desenvolvimento da comunidade, principalmente quando os proprietários moram distante, nas capitais e não no próprio lugar. $\mathrm{E}$ o domínio sôbre a vida política e administrativa é dêsses proprietários.

Por outro lado, a falta de escolas e de outras instituições educacionais concorre, certamente, para o nosso atraso.

Também não é de esquecer a maneira ineficiente pela qual o lavrador tenta arrancar do solo a sua subsistência, adotando, muita vez, em plena era atômica, métodos menos eficientes do que os que foram empregados pelos egípcios, bem no início da história.

Há também e finalmente, a má distribuição da população em muitas comunidades rurais, vivendo mais gente em tantas comunidades, do que ela pode manter. (19).

(17) Lynn Smith, "Brazil, People and Institutions".

(18) T. Lynn Smith, "A organização de atividades de bem-estar na América Latina", trabalho mimeografado.

(19) Ragnar Nurkse, no seu livro Problemas de formação de capital em países subdesenvolvidos tem um capítulo muito interessante sô- 
Lynn Smith não enumerou, porém deve ser acrescentada, aquela mentalidade assistencial com que o nosso povo é tratado e tão comumente aceita, habituando-se a tudo esperar de cima, como favor e graça dos "homens", seja o compadre, o coronel ou o Govêrno. (20). Geralmente, a trôco de fidelidade política, cada vez mais problemática, com o voto secreto e a compra dos sufrágios, tão generalizada.

Pois bem. A cooperativa poderá tornar-se, em cada comunidade, uma importante agência de bem estar, de educação do povo para a democracia, de capacitação integral, desmontando ou desintegrando, a pouco e pouco, o passivismo das populações. Passivismo que era natural, se lhe faltava, como ainda falta, principalmente nos meios rurais, qualquer organização de previdência, apôio legal e suficiente, no isolamento dos sertões, onde o Prefeito, o compadre ou o coronel representam a segurança de uma proteção. ,

Não é apenas com o voto secreto, com uma ilusória capacidade política, se lhe falta todo um lastro econômico e social, que despertaremos a conciência das populações. Nem será também com a quota federal dos municípios, tantas vêzes mal empregada, sem plano, sem ordem, que realizaremos os propalados benefícios de ordem rural.

Não hesitemos em reconhecer, porém, que a própria cooperativa, no Brasil, ainda deverá passar por muitas reformas. Reformas que importarão, acima de tudo, numa fidelida-

bre "O problema da superpopulação rural, e a possibilidade de sua transferência sem reduzir a produção agrícola.

(20) Thales de Azevedo - "As elites de Côr"; Charles Wagley, "Uma Comunidade Amazônicas"; Gylberto Freire, "Compadrio, santas casas e as modernas técnicas de seguro"; Victor Nunez Leal, "Coronelismo, enxada e voto": Costa Porto, "Pinheiro Machado e seu tempo"; Manuel Rodrigues de Melo, "Patriarcas e Carreiros", todos êstes estudam o complexo do compadrio em terras brasileiras. 0 aspecto político é particularmente estudado por Jacques Lambert, "Le Brezil - Strutcture sociale et institutions politiques" e Charles Morazé, "Les 3 âges du Brasil". 
de maior aos mais puros princípios do cooperativismo sadio, já experimentados e vitoriosos em países como a Dinamarca, a Suécia, a Finlândia, a Noruega, para ficar nêstes.

Os atuais desvirtuamentos são frutos dessa falta de mentalidade cooperativista, dessa carência de educação social porular, notando-se, internamente, a falta de participação ativa dos sócios nas assembléias, a omissão de suas atribuições da parte dos Conselhos Fiscais, a aclamação passiva de diretorias cuja eleição sòmente se anima quando o veneno da política procura infiltrar-se.

0 relatório do Banco do Nordeste, referente ao exercício de 1956, tem, a propósito, observações muito justas. Ei-las: “a utilização das cooperativas, como núcleos redistribuidores de crédito aos produtores agrículas é, por certo, o caminho mais curto para ampliar a penetração da Carteira Rural no interior do Polígono das Sêcas... São notórias as deficiências da maioria das cooperativas regionais. Fundamentalmente, falta-lhes, quase sempre, autêntica base cooperativista, isto é, não representam espontânea reunião de pessoas, ou nítida noção do interêsse coletivo e indispensável espírito associativo. Essa anomalia de origem, implica, em grande número de casos, na falta de uma participação efetiva de muitos associados na vida da entidade e na sua consequente estagnação administrativa e financeira. Daí a existência de sociedadés com estrutura frágil e precàriamente organizadas que se caracterizam pelo capital social insignificante, em função do número de associados, e quase ausência de preocupação com a coleta das pequenas poupanças dos cooperados, através dos depósitos. Essas cooperativas deixam de exercer, assim, papel a que hoje se atribui redobrada importância nas áreas subdesenvolvidas, qual seja o de colaborar na formação de capitais e, como é óbvio, não oferecem condições mínimas para atuar como redistribuidoras de recursos do Banco". (21).

(21) Banco do Nordeste do Brasil S/A, Relatório do exercício de 1956, p. 59. 
Já no Relatório do exercício anterior, o mesmo Banco reclamava, com razão, os desvios de doutrina e técnicos, observados em boa parte das cooperativas da região e reclamava melhor organização delas, para o desempenho do seu imprescindível papel, na criação de um autêntico "sistema" de crédito rural. (22).

\section{$V I I-$ Conclusão}

Não se acusem as cooperativas, em si, nem o cooperativismo, pois o instrumento, na sua pureza, é ótimo. 0 defeito está forra, está nos desvirtuamentos. Falta-lhes um ajustamento, que antes de mais nada depende do persistente e incansável trabalho de formação, nos sócios, da mentalidade popular (e não populista) e a capacitação de líderes.

O povo é bem capaz. Está lhe faltando um trabalho educativo sério, cientïficamente organizado, ao qual o serviço social pode prestar colaboração inestimável, aplicando a técnica do "ajudar o povo a ajudar-se a sí mesmo".

A própria cooperativa, ninguém o duvide, graças aos nobres e sedutores princípios que norteiam a instituição, constituirá elemento básico para a eficiente organização da comunidade urbana e rural brasileira, visando o bem estar de todos e de cada um. Esta, a nossa grande tarefa, que não pode parar.

A verdade está com o líder indiano Sudhir Ghosh: "nós não devemos fezê-lo por causa de temor, em nossos corações, de que a alternativa seria o comunismo ou a modificação completa da vida, de natureza violenta. Devemos fazê-lo por causa de nossa convicção profunda de que homens e mulheres, em tôdas as partes do mundo, têm o direito de viver como entes humanos, de crescer e de se desenvolver, e de serem êles próprios". (23).

(22) Banco do Nordeste do Brasil S/A, Relatório do exercício de 1955,
p. 50 .

(23) Sudhir Grosh, trabalho mimeografado apresentado no Seminário Latino-Americano de Bem-Estar Rural. 